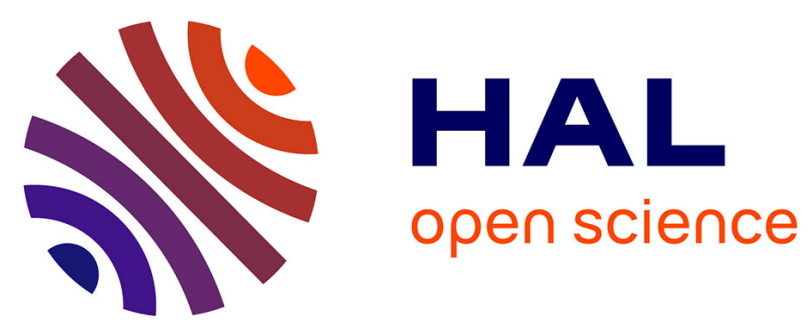

\title{
Reversible Two-Photon Optical Data Storage in Coumarin-Based Copolymers
}

Konstantinos Iliopoulos, Oksana Krupka, Denis Gindre, Marc Sallé

\section{To cite this version:}

Konstantinos Iliopoulos, Oksana Krupka, Denis Gindre, Marc Sallé. Reversible Two-Photon Optical Data Storage in Coumarin-Based Copolymers. Journal of the American Chemical Society, 2010, 132 (41), pp.14343 - 14345. 10.1021/ja1047285 . hal-03343349

\section{HAL Id: hal-03343349 \\ https://univ-angers.hal.science/hal-03343349}

Submitted on 14 Sep 2021

HAL is a multi-disciplinary open access archive for the deposit and dissemination of scientific research documents, whether they are published or not. The documents may come from teaching and research institutions in France or abroad, or from public or private research centers.
L'archive ouverte pluridisciplinaire HAL, est destinée au dépôt et à la diffusion de documents scientifiques de niveau recherche, publiés ou non, émanant des établissements d'enseignement et de recherche français ou étrangers, des laboratoires publics ou privés. 


\title{
Reversible Two-Photon Optical Data Storage in Coumarin-Based Copolymers
}

\author{
Konstantinos Iliopoulos, Oksana Krupka, ${ }^{\ddagger}$ Denis Gindre, ${ }^{\star}$ and Marc Sallé* \\ Laboratoire MOLTECH-Anjou, CNRS UMR 6200, Université d'Angers, 2 Bd Lavoisier, \\ 49045 Angers cedex, France
}

Received May 31, 2010; E-mail: denis.gindre@univ-angers.fr; marc.salle@univ-angers.fr

\begin{abstract}
A functionalized polymer film allowing for a complete and straightforward second-harmonic generation (SHG)-assisted high-contrast writing-reading-erasing-writing sequence is proposed. The whole process is supported by the reversible photoinduced dimerization of a coumarin chromophore and enables efficient optical data storage that can be detected only by SHG imaging.
\end{abstract}

Intensive efforts are continuously produced in the development of novel experimental approaches as well as new materials suitable for the next generations of optical storage devices. Two-photon processes are interesting, as they exhibit a quadratic dependence on the incident light intensity, thus providing a confined recording and, as a result, a high storage capacity. ${ }^{1}$ In the present work, we have designed a class of materials allowing an unprecedented complete and straightforward second-harmonic generation (SHG)assisted writing-reading-erasing-writing sequence with a high contrast, a process that is particularly appealing for optical data storage applications. A myriad of nonlinear optical (NLO) polymers have been synthesized in the last decades by varying the nature of the polymeric backbone and/or the NLO-active chromophores in the side chain. ${ }^{2}$ In this context, a novel concept for recording data based on photoinduced trans-cis isomerization cycles from azo dye polymeric materials was recently reported. ${ }^{3}$ Nevertheless, this system suffers from some drawbacks such as losses of recorded bits along the reading process, since a part of the UV light generated by SHG is absorbed by the azobenzenes and does not allow a straightforward erasing of information.

Coumarin derivatives and analogues are well-known for their photochemical and photophysical properties as well as for their interesting second-order nonlinearities. ${ }^{4}$ In addition, the coumarin unit is known to undergo a reversible photoinduced cyclodimerization by irradiation at $\lambda>300 \mathrm{~nm}$ that leads to stable cyclobutanebased dimers, whereas the reverse photocleavage reaction occurs at shorter wavelengths $(\lambda<280 \mathrm{~nm}) .^{5}$ Therefore, the possibility of tuning these opposite reactions through an external stimulus offers the possibility of controlling the access to two electronically and structurally very different molecular structures. Whereas coumarin chromophores with donating substituents in the 7-position present a suitable delocalization profile for a high dipole moment and an SHG response, formation of the cyclobutane ring in the corresponding dimer prevents $\pi$ conjugation. Moreover, the photodimerization reaction potentially leads to four possible dimer isomers (syn head-to-head, anti head-to-head, syn head-to-tail, and anti headto-tail), an issue that has been used to reach cross-linked polymers upon irradiation at $\lambda>300 \mathrm{~nm}^{4 \mathrm{a}}$ and that also contributes to

* On leave from Kiev National Taras Shevchenko University, Chemistry Department, Ukrain.
Scheme 1. Copolymers Pm and Pm'

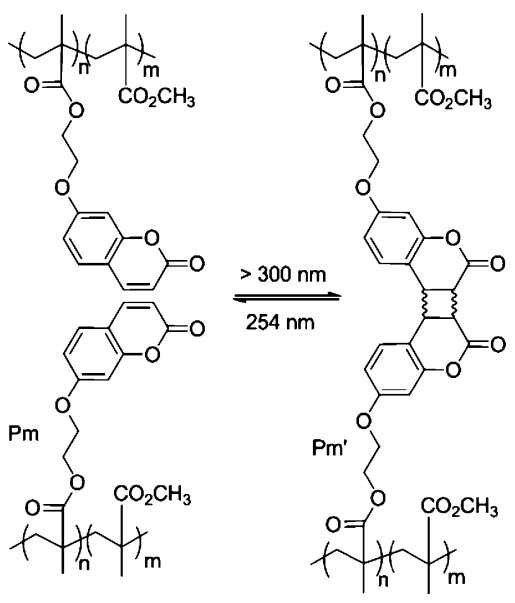

modification of the molecular hyperpolarizability and dipole moment of the resulting system.

On this basis, it was anticipated that cross-coupling between coumarin units grafted to the polymer backbone would induce dramatic changes in the local NLO response of the material and that this change could provide the basis for optical storage devices. An additional property of the coumarin chromophore of interest for this purpose is its transparency in the visible spectrum, which would prevent absorption of the generated SHG photons when $\lambda>$ $750 \mathrm{~nm}$. For this purpose, thin films made of methacrylic copolymers incorporating coumarin side groups as NLO-active molecules were designed.

7-(2-Hydroxyethoxy)coumarin and the 7-(2-methacryloyloxyethoxy)coumarin monomer were prepared through adaptation of reported procedures, ${ }^{5}$ and the copolymer Pm (Scheme 1) was synthesized by free radical polymerization [see the Supporting Information (SI)]. The spin-coating deposition technique was used to produce thin films of $\mathbf{P m}$ on glass slides with a controlled thickness $(1.1 \mu \mathrm{m})$ (see the SI). The optical absorption spectra of $\mathbf{P m}$ in thin films show one major absorption region $(280-350 \mathrm{~nm})$ assigned to the absorption of the coumarin chromophore. The absorption spectra change during irradiation of the film at $\lambda>300$ $\mathrm{nm}$, as presented in Figure S4a in the SI. A progressive decrease in absorbance at $320 \mathrm{~nm}$ corresponding to the coumarin double bond was observed along with formation of the corresponding cyclobutane dimer form $\mathbf{P m}^{\prime}$ (Scheme 1), ${ }^{4 \mathrm{a}, 6}$ whereas Figure S4b illustrates the reverse process from $\mathbf{P m}^{\prime}$ to $\mathbf{P m}$ under irradiation at $\lambda=254 \mathrm{~nm}$. On this basis, the possibility of recording information on Pm films was tested as follows. Prior to optical recording, films of Pm were corona-poled upon heating just below the glass transition temperature $\left(T_{\mathrm{g}}=93^{\circ} \mathrm{C}\right) .{ }^{4 \mathrm{c}}$ The resulting film showed a strong SHG signal that was homogeneous over the film surface and assignable to the coumarin chromophore contribution. No 

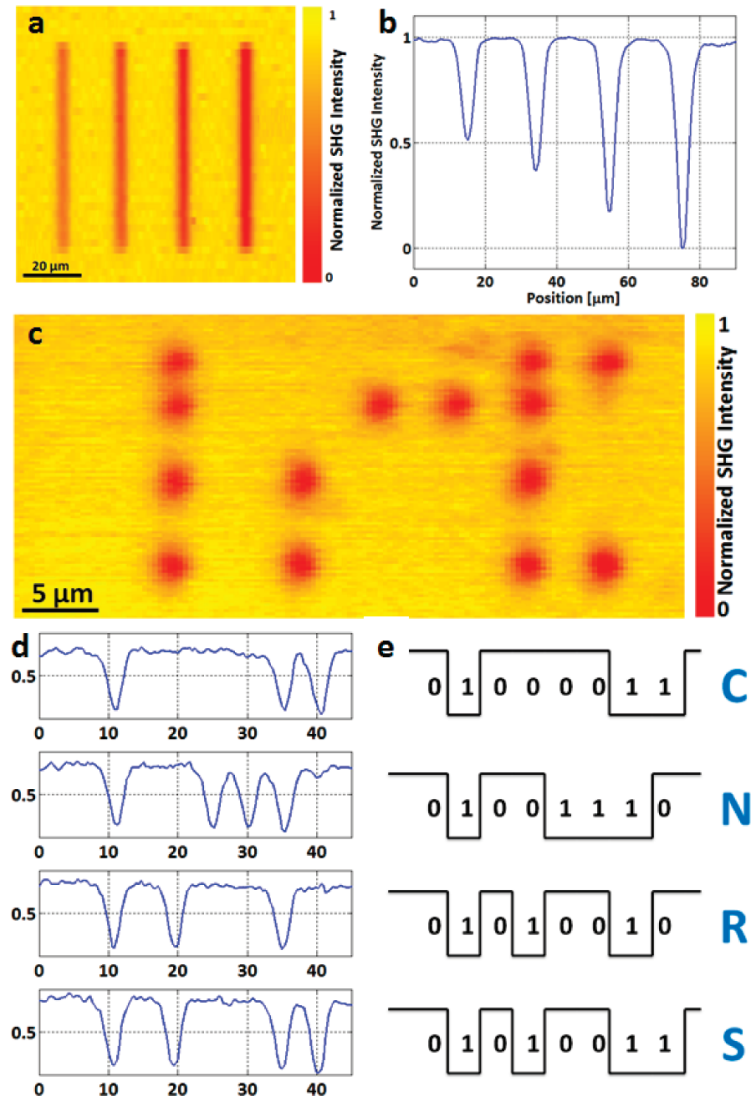

Figure 1. (a) SHG-assisted recording on a $\mathbf{P m}$ film by locally inducing photodimerization of coumarin units [laser power $=20,30,40$, and 50 $\mathrm{mW}$ (left to right) for writing and $16 \mathrm{~mW}$ for reading]. (b) Horizontal SHG profile. (c) ASCII binary recording of the acronym CNRS (for "Centre National de la Recherche Scientifique"). (d) SHG profiles and (e) SHG signal binarization and ASCII decoding corresponding to (c).

alteration of the SHG signal was detected after several weeks. The experimental setup for recording SHG data over the film surface was used as described elsewhere. ${ }^{7}$ A Ti:sapphire laser tunable over the range $670-1100 \mathrm{~nm}$ and providing $120 \mathrm{fs}$ pulses at a repetition rate of $80 \mathrm{MHz}$ was employed (see the SI). Optical recording was achieved by using selective photoinduced dimerization at specific spots on the film surface by steeply focusing the laser beam. During this process, the laser wavelength was set to $700 \mathrm{~nm}$, making available a two-photon process at $350 \mathrm{~nm}$ (close to resonance with the absorption spectrum of the film) for promoting the photodimerization reaction of the coumarin units. In a typical experiment, four vertical lines were recorded ( $5 \mu \mathrm{m} / \mathrm{s}$ ) on a Pm film by varying the laser power. Afterward, reading of the recorded information was carried out by mapping the SHG efficiency over the surface. During this procedure, the laser beam was set to a longer wavelength (800 $\mathrm{nm}$ ) and the laser power was decreased in order to probe the SHG signals without causing any further chemical reaction.

The resulting SHG map is shown in Figure 1a. It can be clearly seen that the level of the SHG signal along the lines where photodimerization occurred strongly differed from the homogeneous background corresponding to the nonrecorded area. As expected from the changes in the chromophore structure, the cross-linked polymer $\mathbf{P m}^{\prime}$ exhibited a remarkably lower SHG efficiency than the initial coumarin-based Pm film. This observation is even more evident in Figure 1b, which shows the horizontal profile of the SHG response. Interestingly, increasing the laser power did not result in any saturation effect; the contrast between the SHG levels of the recorded and nonrecorded areas increased. Atomic force microscopy

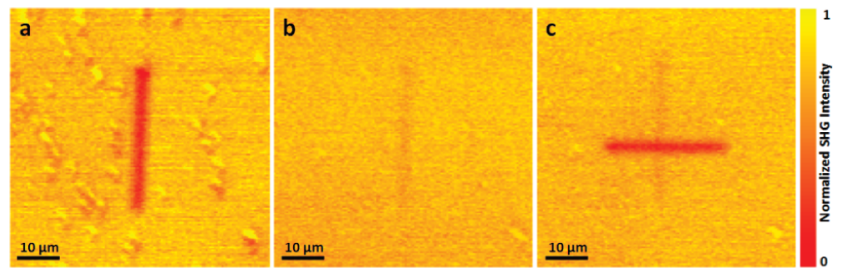

Figure 2. (a) SHG image (readout at $\lambda=800 \mathrm{~nm}$ ) after a line was written at $\lambda=700 \mathrm{~nm}$. (b) SHG image after irradiation of the area with a UV reactor $(\lambda=250 \mathrm{~nm})$. (c) SHG image after a new line was written perpendicular to the first one.

(AFM) measurements were carried out to check that no damage or surface alteration occurred during the reading and writing processes (see the SI). The surface of the film was not altered at all, opening promising perspectives for linearly undetectable 3D storage applications. As an illustrative example of the potential offered by this procedure, the acronym CNRS was recorded on a thin film using ASCII binary characters (Figure 1c). The spots corresponding to " 1 " bits were produced by irradiation of Pm for $200 \mathrm{~ms}$. The horizontal SHG profiles are presented in Figure 1d and the corresponding binarization process in Figure 1e, illustrating the level of control over the contrast between the two states.

Moreover, the possibility of rewriting information in the same area was experimentally demonstrated through the following procedure. Typically, a vertical line was first recorded on a film $(\lambda$ $=700 \mathrm{~nm}, 25 \mathrm{~mW}$ ) (Figure 2a). Afterward, the film surface was exposed to UV light (see the SI) in order to enable erasing of the recorded information by converting the written part $\left(\mathbf{P m}^{\prime}\right)$ back to Pm. SHG imaging was then carried out and revealed that the previously recorded information had been erased (Figure 2b). Finally, the reusable character of the film was demonstrated by recording a horizontal line in the same area (Figure 2c). Notably, the last step was carried out without the need for a second corona poling of the film.

A novel experimental approach using SHG printing and imaging that is based on the reversible photodimerization of a coumarin chromophore enables highly efficient optical data storage. A highcontrast writing-reading sequence has been carried out and shown to be reversible through a straightforward erasing procedure, offering the added possibility of writing new inputs in the same area. Finally, it is worth noting that the reading procedure can be carried out only by SHG imaging and that no modification of the film surface could be detected, opening promising perspectives in the important and sensitive field of hidden 3D data storage.

Acknowledgment. The authors thank C. Cassagne, A. Mahot, J. Benoist, and F. Le Derf for their technical help as well as Sandie Piogé, Dr. V. Montembault, and Prof. L. Fontaine (University of Le Mans, Laboratory UCO2M) for technical assistance with the gel permeation chromatography studies. We thank the Region Pays de la Loire for financial support of this project (MOLTECH-Anjou).

Supporting Information Available: Polymer synthesis, spectroscopic characterizations of films, SHG microscopy setup, and AFM studies. This material is available free of charge via the Internet at http://pubs.acs.org.

\section{References}

(1) (a) Parthenopoulos, D. A.; Rentzepis, P. M. Science 1989, 245, 843-845. (b) Pudavar, H. E.; Joshi, M. P.; Prasad, P. N.; Reinhardt, B. A. Appl. Phys. Lett. 1999, 74, 1338-1340. (c) Li, X.; Chon, J. W. M.; Evans, R. A.; Gu, M. Appl. Phys. Lett. 2008, 92, 063309. (d) Corredor, C. C.; Huang, Z.-L.; Belfield, K. D. Adv. Mater. 2006, 18, 2910-2914. (e) Yuan, W.; Sun, L.; Tang, H.; Wen, Y.; Jiang, G.; Huang, W.; Jiang, L.; Song, Y.; Tian, H.; Zhu, D. Adv. Mater. 2005, 17, 156-159. (f) Marder, S. R. Chem. Commun. 
2006, 131-134. (g) Zijlstra, P.; Chon, J. W. M.; Gu, M. Nature 2009, 459, 410-413. (h) Li, L.; Yang, J.; Wang, C.; Hu, Z.; Tian, Y.; Li, J.; Wang, C.; Li, M.; Cheng, G.; Tang, H.; Huang, W.; Tao, X.; Jiang, M. Sci. China, Ser. B: Chem. 2010, 53, 884-890.

(2) (a) Cho, M. J.; Choi, D. H.; Sullivan, P. A.; Akelaitis, A. J. P.; Dalton, L. R. Prog. Polym. Sci. 2008, 33, 1013-1058. (b) Delaire, J. A.; Nakatani, K. Chem. Rev. 2000, 100, 1817-1846. (c) Coe, B. J. Chem.-Eur. J. 1999 5, 2464-2471. (d) Samyn, C.; Verbiest, T.; Persoons, A. Macromol. Rapid Commun. 2000, 21, 1-15.

(3) Gindre, D.; Boeglin, A.; Taupier, G.; Crégut, O.; Vola, J.-P.; Barsella, A.; Mager, L.; Fort, A.; Dorkenoo, K. D. J. Opt. Soc. Am. B 2007, 24, 532 537.

(4) (a) Trenor, S. R.; Shultz, A. R.; Love, B. J.; Long, T. E. Chem. Rev. 2004 104, 3059-3077. (b) Moylan, C. R. J. Phys. Chem. 1994, 98, 13513-13516. (c) Mortazavi, M. A.; Knoesen, A.; Kowel, S. T; Henry, R. A.; Hoover, J. M.; Lindsay, G. A. Appl. Phys. B: Lasers Opt. 1991, 53, 287-295. (d) Belfield, K. D.; Bondar, M. V.; Liu, Y.; Przhonska, O. V. J. Phys. Org. Chem. 2003, 16, 69-78. (e) Zhao, L.; Vaupel, M.; Loy, D. A.; Shea, K. J. Chem Mater 2008, 20, 1870-1876. (f) Wolff, T. Görner, H. J. Photochem. Photobiol., A 2010, 209, 219-223.

(5) (a) Obi, M.; Morino, S.; Ichimura, K. Chem. Mater. 1999, 11, 656-664. (b) Traeger, J.; Heinzer, J.; Kim, H.-C.; Hampp, N. Macromol. Biosci. 2008, 8, $177-183$.

(6) Chen, Y.; Geh, J. L. Polymer 1996, 37, 4481.

(7) Gindre, D.; Boeglin, A.; Fort, A.; Mager, L.; Dorkenoo, K. D. Opt. Express 2006, 14, 9896-9901.

JA1047285 